Revista Brasileira de Agricultura Irrigada v.5, nº. 3, p.188- 201, 2011

ISSN 1982-7679 (On-line)

Fortaleza, CE, INOVAGRI - http://www.inovagri.org.br

Protocolo 057 11-04/05/2011 Aprovado em 22/09/2011

\title{
IDENTIFICAÇÃO E QUANTIFICAÇÃO DO EFEITO DE FATORES AMBIENTAIS NA PRODUTIVIDADE DA CULTURA DO MILHO NA REGIÃO DE JANAÚBA, MG
}

\author{
Maria Emília Borges Alves ${ }^{1}$, Camilo de Lelis Teixeira de Andrade ${ }^{2}$, Ramiro Ruiz- \\ Cárdenas $^{3}$, Tales Antônio Amaral ${ }^{4}$, Denise Freitas Silva ${ }^{5}$
}

\footnotetext{
${ }^{1}$ Engenheira Agrícola, DSc, bolsista pós-doutorado FAPEMIG, Embrapa Milho e Sorgo, Rod. MG 424 KM 65, CP 151, 35.701-970 - Sete Lagoas, MG, e-mail: mebalves@ hotmail.com

${ }^{2}$ Engenheiro Agrícola, PhD, pesquisador Embrapa Milho e Sorgo, Rod. MG 424 KM 65, CP 151, 35.701-970 - Sete Lagoas, MG, e-mail: camilo@cnpms.embrapa.br

${ }^{3}$ Engenheiro Agrônomo, DSc, bolsista pós-doutorado CAPES/PRODOC, Departamento de Estatística, Universidade Federal de Minas Gerais, UFMG, Campus Pampulha, 31.270-901 - Belo Horizonte, MG, e-mail: ramiro@est.ufmg.br ${ }^{4}$ Biólogo, MSc, doutorando em Sistemas de Produção Agrícola Familiar - SPAF, Universidade Federal de Pelotas UFPEL, CP 354, 96.010-900, Pelotas RS, e-mail: tales_aamaral@yahoo.com.br

${ }^{5}$ Engenheira Agrícola, DSc, bolsista pós-doutorado CNPq, EMBRAPA Milho e Sorgo, Rod. MG 424 KM 65, CP 151,35.701-970 - Sete Lagoas, MG, e-mail: denise@ cnpms.embrapa.br
}

RESUMO: Na região do semiárido do Estado de Minas Gerais, Brasil, há um grande déficit na oferta de milho, mesmo para subsistência familiar. $\mathrm{O}$ entendimento dos fatores que afetam a produtividade desta cultura é crucial para o desenvolvimento de estratégias de manejo adequadas. Neste contexto, o objetivo deste trabalho foi identificar os fatores climáticos que podem influenciar a produtividade da cultura do milho na região de Janaúba, MG, e quantificar o grau de influência desses fatores, a partir da análise de dados de produtividade da cultura simulados com o modelo CSMCERES-Maize. O modelo foi utilizado para simular o rendimento de grãos de milho semeado semanalmente ao longo do ano, em condições de sequeiro e irrigado no período de 1977 a 2008. A análise estatística indicou que os fatores data da semeadura, ano e irrigação (sequeiro e irrigado) e suas interações duplas foram significativos ao nível de significância de 5\%. A disponibilidade hídrica foi responsável pela maior proporção da variação total na produtividade de milho na região de estudo $(61,9 \%)$, seguida pela data de semeadura e suas interações duplas com os outros fatores $(26,2 \%)$. Em condições ótimas de disponibilidade hídrica (cultivo irrigado), os fatores, que mais influenciam o rendimento da cultura do milho são, basicamente, a variações de temperatura do ar e a radiação solar incidente. Fato evidenciado pelos baixos valores de produtividade simulada encontrados em anos nos quais a radiação solar incidente ficou abaixo da média geral observada.

Palavras chave: radiação, DSSAT, disponibilidade de água, temperatura

\section{IDENTIFICATION AND EFFECT QUANTIFICATION OF ENVIRONMENTAL FACTORS ON MAIZE YEILD FOR JANAÚBA, MG REGION}

ABSTRACT:In semiarid region of Minas Gerais State, Brazil, there is a large deficit on maize supply, even for family livelihood. Understanding factors that affect maize yield is crucial to develop appropriate crop management strategies. The study aimed at to 


\section{IDENTIFICAÇÃO E QUANTIFICAÇÃO DO EFEITO DE FATORES AMBIENTAIS NA PRODUTIVIDADE DA CULTURA DO MILHO NA REGIÃO DE JANAÚBA, MG}

identifying climatic factors that affect maize yield in Janauba, MG, Brazil, and quantify the degree of influence of climate elements by using crop yield data simulated with CSM-CERES-Maize model. The model was used to simulate maize yield sowed weekly throughout the year, under irrigated and rainfed conditions, from 1977 to 2008. Statistical analysis performed on simulated yield data indicated that the factors sowing date, year and irrigation (rainfed and irrigated) and their double interactions were significant at a 5\% level. The water availability accounted for the greatest amount of total maize yield variation in the study region (61.9\%), followed by sowing date and its second order interactions (26.2\%). Under optimal water availability conditions (irrigated), the factors that most influence the yield of maize are, basically, the air temperature and solar radiation variations. This fact was evidenced by low productivity values found in years that the incident solar radiation was below the observed average.

Keywords: radiation, DSSAT, water availability, temperature

\section{INTRODUÇÃO}

A planta de milho é considerada uma das mais eficientes na conversão de energia radiante e, consequentemente, na produção de biomassa. No entanto, de acordo com Andrade (1995), apesar do elevado potencial produtivo, o milho apresenta acentuada sensibilidade a estresse de natureza biótica e abiótica, que aliada a sua pequena plasticidade foliar, reduzida prolificidade e baixa capacidade de compensação efetiva, faz com que o seu cultivo necessite ser rigorosamente planejado e criteriosamente manejado, objetivando a manifestação de sua capacidade produtiva.

Assim, a identificação e quantificação da influência dos fatores que determinam o desempenho da planta poderão contribuir de forma decisiva para a minimização de estresses de natureza diversa. A predição ou previsão da duração das fases de desenvolvimento da planta poderá ser realizada e o planejamento de plantio realizado de forma a evitar a coincidência dessas fases com condições desfavoráveis de oferta dos fatores de produção (FANCELLI, 2000). O conhecimento dos elementos climáticos de uma região é útil na determinação dos períodos críticos predominantes, permitindo, assim, o planejamento das semeaduras de forma a reduzir os efeitos negativos sobre a produtividade das culturas (ASSIS, 2006).

A semeadura do milho na época adequada é um procedimento que não afeta os custos inerentes ao plantio, mas seguramente afetará o rendimento e, consequentemente, o lucro do agricultor (FORSTHOFER et al., 2006). Esta é uma estratégia que deve ser adotada mesmo em condições de plantio irrigado, pois, outros fatores ambientais, como a radiação solar e a disponibilidade térmica podem exercer influência sobre o crescimento e o desenvolvimento da cultura, podendo ocorrer diminuição na produção de grãos devido a estes fatores, ainda que em condições adequadas de suprimento de água (LOZADA et al., 1999). Didonet et al. (1998) e Wilson et al. (1995) afirmam que se o suprimento de água e de nutrientes minerais são suficientes, a taxa de crescimento de milho depende basicamente de temperatura e de intensidade de luz.

Uma grande variabilidade, tanto interanual, quanto sazonal, nos valores da produtividade de grãos simulados pelo modelo CSM-CERES-Maize, mesmo em condições de irrigação automática, foi observada por Andrade et al. (2009a; 2009b), indicando que 


\section{IDENTIFICAÇÃO E QUANTIFICAÇÃO DO EFEITO DE FATORES AMBIENTAIS NA PRODUTIVIDADE DA CULTURA DO MILHO NA REGIÃO DE JANAÚBA, MG}

outros fatores, além do estresse hídrico, afetam consideravelmente a produtividade do milho. Esses autores destacam que o período de semeadura capaz de proporcionar as maiores produtividades de grãos, sob irrigação, é diferente daquele recomendado para o sistema de sequeiro.

$\mathrm{O}$ estudo do potencial de rendimento de grãos de milho, em diferentes níveis de manejo e épocas de semeadura, possibilita a identificação dos fatores ambientais que limitam seu cultivo, em cada época de semeadura. Com base no conhecimento e na mensuração dos fatores que interferem no rendimento de grãos, nos diferentes níveis e sistemas produtivos, poderão ser traçadas estratégias de manejo e adotadas indicações viáveis, para minimizar ou superar as deficiências verificadas em cada nível de manejo utilizado (FORSTHOFER et al., 2006).

Como há interação entre os diversos fatores que afetam o desenvolvimento e a produtividade das culturas, a individualização do efeito é difícil de ser quantificada, podendo ser facilitada, todavia, com o uso da modelagem. $\mathrm{O}$ modelo Cropping System Model (CSM)-CERES-Maize, do sistema DSSAT (Decision Support System for Agrotechnology Transfer) (HOOGENBOOM et al., 2009), pode ser usado para simular a produtividade das culturas e auxiliar na definição de estratégias que permitam um melhor aproveitamento dos recursos naturais (ANDRADE et al., 2009a). Os modelos do grupo DSSAT se baseiam em quatro tipos de variáveis de entrada: solo, clima, manejo do cultivo e genótipos (TOJO SOLER, 2004) e simulam os principais processos envolvidos no crescimento de diversas culturas de grãos, hortaliças e pastagens (HOOGENBOOM et al, 2009).
Andrioli e Sentelhas (2009) afirmam que o uso de modelos de produção bem calibrados resulta em estimativas aceitáveis de produtividade, e tem potencial para ser usado como preditor de produtividade, para $\mathrm{o}$ zoneamento de culturas e para uma melhor determinação de épocas de semeadura.

O objetivo deste trabalho foi identificar os fatores climáticos que influenciam a produtividade da cultura do milho na região de Janaúba, MG, e quantificar o grau de influência desses fatores, a partir da análise de dados de produtividade da cultura simulados com o modelo CSM-CERES-Maize.

\section{MATERIAL E MÉTODOS}

Empregou-se o modelo CSMCERES-Maize, do DSSAT, versão 4.5, previamente calibrado e avaliado, para simular o rendimento de grãos de milho, semeado semanalmente ao longo do ano, em Janaúba, MG, cujas coordenadas geográficas são $15^{\circ} 48^{\prime} 09^{\prime}$ " $\mathrm{S}, 43^{\circ} 18^{\prime} 32^{\prime}$ 'W e $516 \mathrm{~m}$ de altitude.

As simulações foram realizadas empregando-se a ferramenta de análise sazonal do modelo CSM-CERESMaize, considerando condições de manejo fitotécnico para a produção em regime de sequeiro e irrigado. Utilizaram-se dados diários de precipitação, de temperatura máxima e mínima do ar e de radiação solar incidente, obtidos de uma série histórica com 32 anos de registros da estação meteorológica do INMET (Instituto Nacional de Meteorologia) instalada no município de Janaúba, compreendendo o período de 1977 a 2008. Considerouse a cultivar BRS 1030, previamente calibrada por Santana et al. (2010), semeada com espaçamento de $0,9 \mathrm{~m}$ entre linhas e 65 mil plantas por ha e cultivada sem restrições nutricionais. Considerou-se 52 datas de semeadura 


\section{IDENTIFICAÇÃO E QUANTIFICAÇÃO DO EFEITO DE FATORES AMBIENTAIS NA PRODUTIVIDADE DA CULTURA DO MILHO NA REGIÃO DE JANAÚBA, MG}

(Tabela 1), de forma que, para cada data de semeadura e nível de irrigação, foram simulados 32 dados de produtividade anual de grãos.

Tabela 1: Tratamentos simulados com suas respectivas datas de semeadura

\begin{tabular}{cccccccc}
\hline Trat & Data & Trat & Data & Trat & Data & Trat & Data \\
\hline 1 & 1-Ago & 14 & 31- Out & 27 & 30-Jan & 40 & 1-Mai \\
2 & 8- Ago & 15 & 7-Nov & 28 & 6-Fev & 41 & 8- Mai \\
3 & 15- Ago & 16 & 14-Nov & 29 & 13- Fev & 42 & 15- Mai \\
4 & 22- Ago & 17 & 21-Nov & 30 & 20- Fev & 43 & 22- Mai \\
5 & 29- Ago & 18 & 28-Nov & 31 & 27- Fev & 44 & 29- Mai \\
6 & 5-Set & 19 & 5-Dez & 32 & 6-Mar & 45 & 5-Jun \\
7 & 12- Set & 20 & 12- Dez & 33 & 13-Mar & 46 & 12-Jun \\
8 & 19-Set & 21 & 19- Dez & 34 & 20-Mar & 47 & 19-Jun \\
9 & 26- Set & 22 & 26- Dez & 35 & 27-Mar & 48 & 26-Jun \\
10 & 3-Out & 23 & 2-Jan & 36 & 3-Abr & 49 & 3-Jul \\
11 & 10- Out & 24 & 9-Jan & 37 & 10- Abr & 50 & 10-Jul \\
12 & 17- Out & 25 & 16-Jan & 38 & 17- Abr & 51 & 17-Jul \\
13 & 24- Out & 26 & 23-Jan & 39 & 24- Abr & 52 & 24-Jul \\
\hline
\end{tabular}

Nas simulações para condições de manejo irrigado, considerou-se o sistema de irrigação por aspersão, com eficiência global de $100 \%$, sendo a eficiência global equivalente a relação entre a água agregada à zona radicular e a quantidade fornecida a todo o projeto de irrigação. A irrigação foi programada para ser aplicada automaticamente de acordo com a necessidade da cultura. Assumiu-se uma profundidade de controle de 0,30 m (profundidade onde se concentra maior parte do sistema radicular do milho), e um fator de depleção de $50 \%$ da água disponível do solo, a fim de garantir uma umidade de segurança que permitisse o perfeito desenvolvimento da cultura. As lâminas de irrigação foram calculadas de forma que a umidade do solo atingisse a capacidade de campo a cada irrigação aplicada, propiciando à cultura condições ótimas de disponibilidade de água e, assim, permitindo a realização das análises propostas para as condições de manejo irrigado.

Os dados de produtividade alcançados após simulação com o modelo foram submetidos a análise de variância para determinar a contribuição de cada um dos fatores principais, data de semeadura, irrigação, ano e de suas interações, à variação total da produtividade. No modelo de simulação CSM-CERES-Maize, o crescimento e desenvolvimento da cultura são simulados de forma determinística através de um complexo sistema de equações diferenciais, resultando em predições exatas das variáveis de interesse, isto é, sem qualquer distribuição de probabilidade ou elementos aleatórios associados, conforme descreve Jones (1986). No entanto, essa natureza determinística do modelo impossibilita ter replicações dos diferentes tratamentos. Portanto, a variância residual não é estimável, isto é, o efeito da interação tripla (data de semeadura $\mathrm{x}$ ano $\mathrm{x}$ irrigação) e o erro experimental não podem ser separados. Assim, visando testar a significância dos principais fatores e suas interações duplas foi assumido que o efeito dessa interação tripla era desprezível. Sob essa suposição, a soma de quadrados da 


\section{IDENTIFICAÇÃO E QUANTIFICAÇÃO DO EFEITO DE FATORES AMBIENTAIS NA PRODUTIVIDADE DA CULTURA DO MILHO NA REGIÃO DE JANAÚBA, MG}

interação tripla fornece uma estimativa da variância do erro experimental. A significância das interações duplas foi também verificada através de um teste de não-aditividade (TUKEY, 1949) ao nível de significância de 5\%. Todas as análises foram realizadas usando o software estatístico $\quad \mathrm{R}$, versão $\quad 2.11 .1 \quad(\mathrm{R}$ DEVELOPMENT CORE TEAM, 2010).

\section{RESULTADOS E DISCUSSÃO}

Na Figura 1 são apresentadas as distribuições de frequiência da produtividade de grãos de milho simulada, para diferentes datas de semeadura, nas condições de manejo de sequeiro (Figura 1A) e irrigado (Figura 1B).
(A)

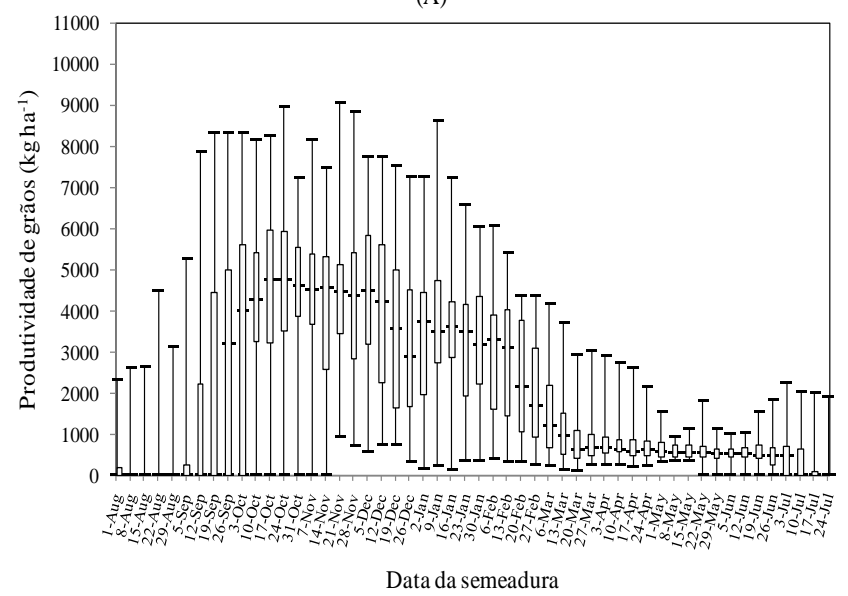

(B)

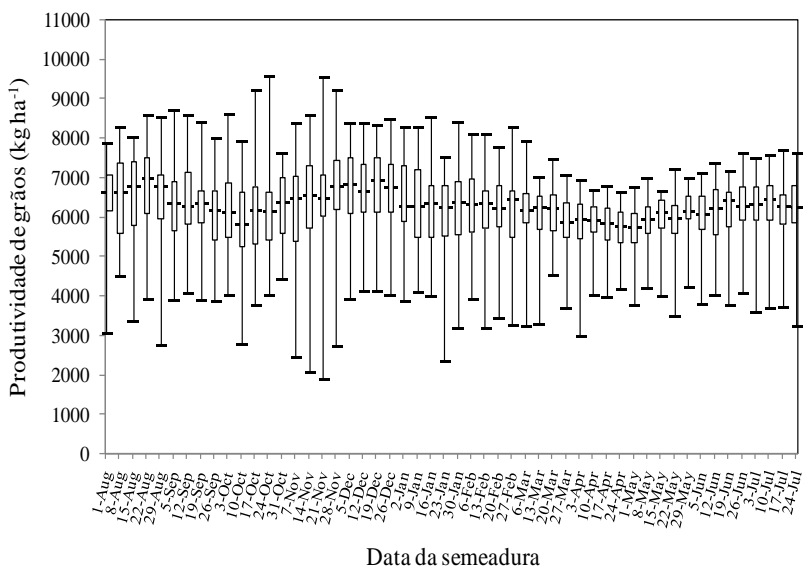

Figura 1: Distribuição de freqüência da produtividade de grãos de milho, indicando valores mínimos, máximos, medianos e percentis $(25 \%, 50 \%$ e $75 \%)$, para o município de Janaúba, MG, para diferentes datas de semeadura nas condições de manejo de sequeiro (A) e irrigado (B).

A variabilidade encontrada no cultivo sob as condições de manejo de sequeiro pode ser entendida como decorrente da variação na disponibilidade hídrica, pois, segundo Bergamaschi et al. (2004), a água é o principal fator condicionante das safras de milho nas regiões produtoras ao redor do mundo.

Ao se comparar a produtividade média simulada e a precipitação média observada ao longo dos 32 anos do estudo (Figura 2), para diferentes datas de plantio e considerando que a cultura do milho exige um mínimo de 400-600 $\mathrm{mm}$ de precipitação pluvial para que possa manifestar seu potencial produtivo sem a necessidade da utilização da prática de irrigação (FANCELLI, 2000), constata-se que a produtividade média esteve sempre abaixo da média nacional, que é de 3.700 kg.ha- ${ }^{-1}$ (PEIXOTO, 2010), quando a precipitação média foi menor que $400 \mathrm{~mm}$. Cruz et al. (2010) afirmam que a ocorrência de déficit hídrico na cultura do milho pode ocasionar danos em todas as fases de desenvolvimento da cultura. Bergamaschi et al. (2006) observaram em trabalho conduzido ao longo de 10 anos de cultivo de milho, no estado do Rio Grande do Sul, que a produtividade média da cultura atingiu 10,4 $\mathrm{t} \mathrm{ha}^{-1}$, sob manejo irrigado e, em $50 \%$ dos anos, a produtividade média não atingiu $6 \mathrm{t} \mathrm{ha}^{-1}$, sob manejo de sequeiro, constatando uma grande variabilidade interanual, nestas condições, com os rendimentos variando entre 10 e 1,5 t ha $^{-1}$. 


\section{IDENTIFICAÇÃO E QUANTIFICAÇÃO DO EFEITO DE FATORES AMBIENTAIS NA PRODUTIVIDADE DA CULTURA DO MILHO NA REGIÃO DE JANAÚBA, MG}

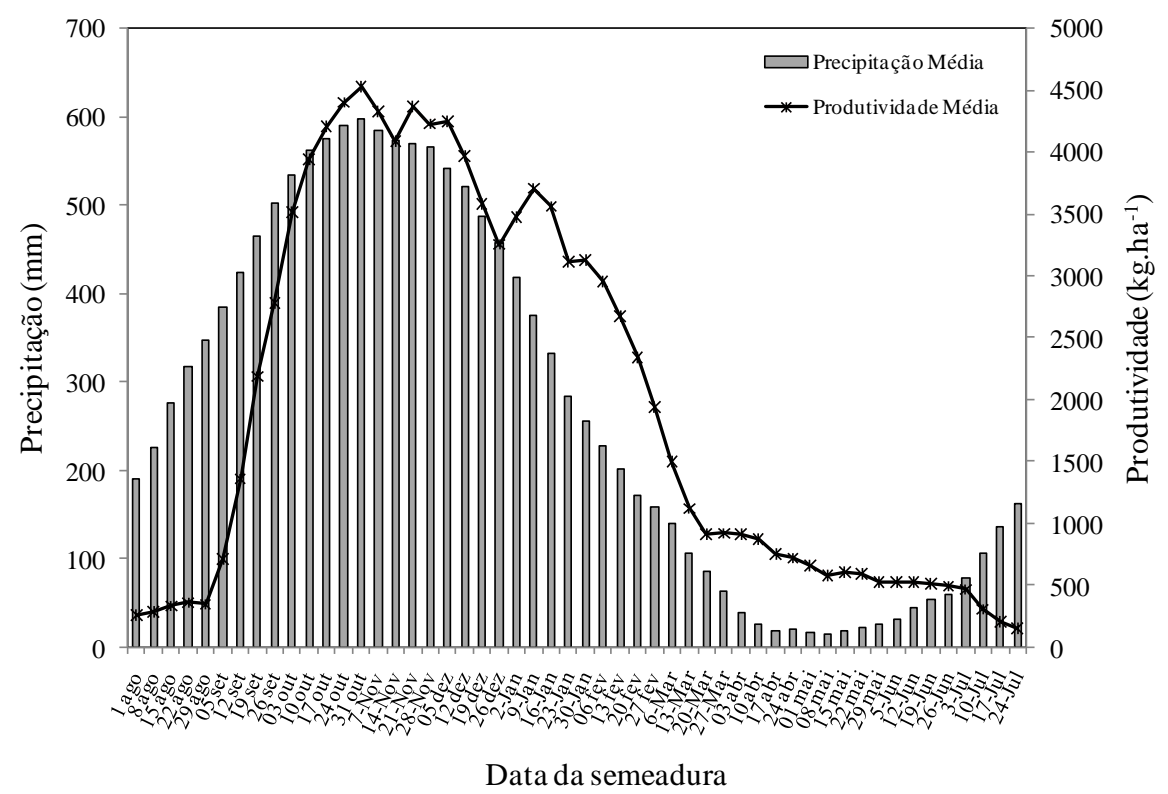

Figura 2: Relação entre a produtividade média simulada e a precipitação média observada em 32 anos, para diferentes datas de semeadura da cultura do milho, sob condições de manejo de sequeiro.

Observou-se, no entanto, que houve uma variação estacional e interanual da produtividade de grãos, mesmo com a cultura mantida em condições adequadas de umidade no solo por meio do manejo irrigado (Figura 1B), com variações consideráveis entre as produtividades máximas e mínimas em todas as datas de semeadura, indicando que outros fatores, além de estresse hídrico, afetam significativamente $\mathrm{o}$ rendimento da cultura. Tal fato foi também observado por Andrade et al. (2009a), quando avaliaram a produtividade do milho em diferentes datas de semeadura, para a região de Sete Lagoas, MG, destacando a hipótese de que fatores como temperatura e radiação podem influenciar no comprimento do ciclo da cultura, na produção de fotoassimilados e no acúmulo de massa seca, afetando diretamente a produtividade da cultura.

Os três fatores principais (manejo irrigado e de sequeiro), irrigação, data de semeadura e ano, e suas interações duplas foram significativos ao nível de significância de 5\% (Tabela 2).

Tabela 2: Resumo da análise de variância (ANOVA) para a variável produtividade simulada da cultura do milho sob a influência dos fatores de variação época de plantio, ano e irrigação

\begin{tabular}{llllll}
\hline Fator de variação & GL & SQ & SQM & F & Pr $(>\mathrm{F})$ \\
\hline Data de semeadura & 51 & 2248,9 & 44,1 & 37,88 & $2,2 \times 10^{-16} * * *$ \\
Ano & 31 & 422,5 & 13,6 & 11,71 & $2,2 \times 10^{-16} * * *$ \\
Irrigação & 1 & 14644,1 & 14644,1 & 12580,27 & $2,2 \times 10^{-16} * * *$ \\
Data de semeadura x Irrigação & 51 & 1834,5 & 36,0 & 30,90 & $2,2 \times 10^{-16} * * *$ \\
Ano x Irrigação & 31 & 563,8 & 18,2 & 15,62 & $2,2 \times 10^{-16} * * *$ \\
Data de semeadura x Ano & 1581 & 2103,9 & 1,3 & 1,14 & $0,003915 * *$ \\
Resíduo & 1581 & 1840,4 & 1,2 & & \\
\hline
\end{tabular}

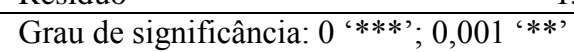




\section{IDENTIFICAÇÃO E QUANTIFICAÇÃO DO EFEITO DE FATORES AMBIENTAIS NA PRODUTIVIDADE DA CULTURA DO MILHO NA REGIÃO DE JANAÚBA, MG}

$\mathrm{Na}$ figura 3 é representada graficamente a significância encontrada nas interações duplas entre os fatores principais, irrigação, data de semeadura e ano. A Figura $3 \mathrm{~A}$ apresenta a média da produtividade simulada em cada um dos 52 níveis do fator data de semeadura para cada nível do fator irrigação. Similarmente, a figura 3B apresenta a média da produtividade simulada em cada um dos 32 níveis do fator ano para cada nível do fator irrigação. $\mathrm{O}$ cruzamento entre as retas nos dois gráficos (ausência de paralelismo) evidencia a presença de uma interação dupla significativa entre os fatores irrigação versus data de semeadura e irrigação versus ano, como verificado nos resultados da análise de variância

na Tabela

2.

\section{(A)}

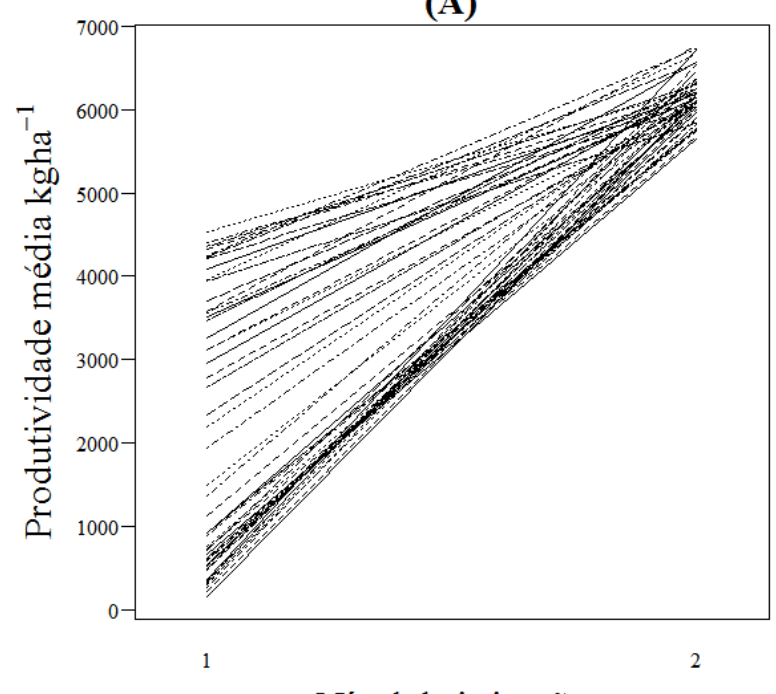

Nível de irrigação

(B)

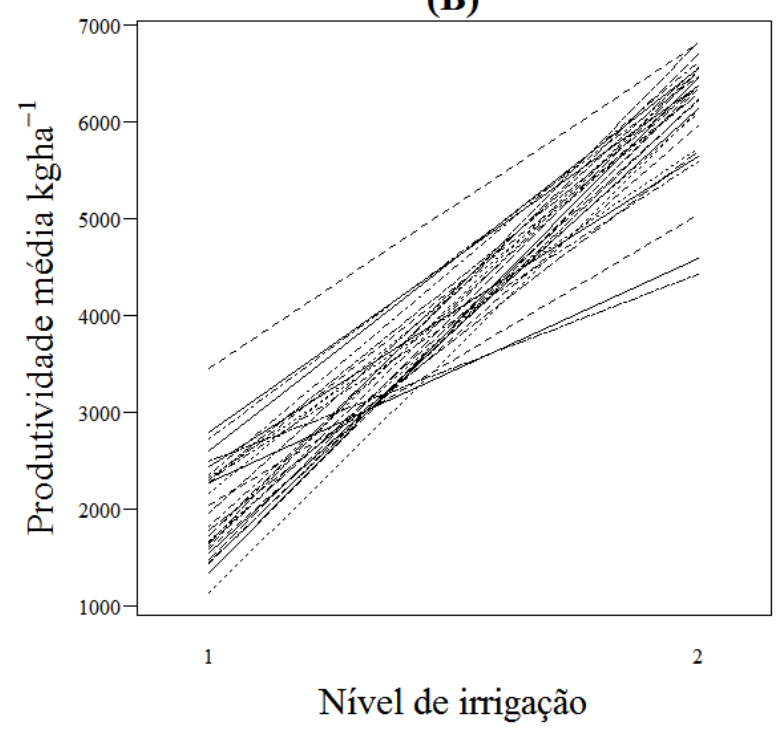

Figura 3: Produtividade simulada (média dos 32 anos) para as 52 semanas do ano na interação irrigação $x$ data de semeadura (A) e produtividade simulada (média das 52 datas de semeadura) para os 32 anos na interação irrigação x ano (B).

A contribuição de cada fonte de variação à variação total, expressa como uma porcentagem da sua soma de quadrados em relação à soma de 


\section{IDENTIFICAÇÃO E QUANTIFICAÇÃO DO EFEITO DE FATORES AMBIENTAIS NA PRODUTIVIDADE DA CULTURA DO MILHO NA REGIÃO DE JANAÚBA, MG}

quadrados total é apresentada na Tabela 3. Observa-se que, em uma análise geral, a irrigação, ou seja, a disponibilidade hídrica, explica $61,9 \%$ da variação total da produtividade. Neste contexto, Bergamaschi et al. (2004) concluíram que, independentemente da condição climática da região de implantação da cultura, a produtividade de grãos de milho é decorrente das condições hídricas durante o período crítico, que se estende desde o pendoamento até o início do enchimento de grãos.
Diante disso, irrigações durante o período crítico permitem elevada produtividade de grãos de milho, mesmo que a umidade do solo seja mantida abaixo da capacidade de campo. Entretanto, para Janaúba, MG, nota-se que $38,1 \%$ da variabilidade observada na produtividade do milho são decorrentes de outros fatores, sendo que aproximadamente $26 \%$ são decorrentes do fator data de semeadura e suas interações com os demais fatores.

Tabela 3: Contribuição à variação total de cada fonte de variação, expressa como uma porcentagem da sua soma de quadrados (SQ\%) para a soma de quadrados total

\begin{tabular}{lc}
\hline Fator de variação & SQ $(\%)$ \\
\hline Data de semeadura & 9,51 \\
Ano & 1,79 \\
Irrigação & 61,90 \\
Data de semeadura x Irrigação & 7,75 \\
Ano x Irrigação & 2,38 \\
Data de semeadura x Ano & 8,89 \\
Resíduo & 7,78 \\
\hline
\end{tabular}

Não havendo restrição hídrica, a data de semeadura pode influenciar a produtividade do milho basicamente devido a variações de temperatura e radiação solar incidente. Variações típicas sazonais destas variáveis podem ser previstas por meio de modelagem, com base em séries históricas de clima e, a partir delas, é possível estabelecer datas de semeadura que propiciem maiores produtividades. A quantidade de radiação incidente disponível, por exemplo, varia com a posição geográfica da região, ou seja, com sua latitude e altitude e com a época de semeadura da cultura (FORSTHOFER et al, 2006).

$\mathrm{O}$ ano de plantio influencia a produtividade em decorrência das mesmas variáveis climáticas que a data de semeadura, ou seja, temperatura e radiação. No entanto, para data de semeadura estas variáveis sofrem efeitos sazonais e o mesmo não acontece de ano para ano. Isto se dá porque, caso ocorram variações destas variáveis entre os anos, elas serão decorrentes de eventos climáticos atípicos ou anômalos, de forma que a previsão de condições desfavoráveis ao cultivo do milho em função do ano de plantio se torna limitada, exatamente pela eventualidade com que eles ocorrem.

Variações singulares na evolução anual da radiação média diária foram observadas por Gomes et al. (2006) em sete anos de dados observados na região de Botucatu, SP, tendo sido estas variações dependentes das condições atmosféricas relacionadas à nebulosidade e precipitação para cada ano. Variações na radiação solar incidente, naturalmente, implicam em 


\section{IDENTIFICAÇÃO E QUANTIFICAÇÃO DO EFEITO DE FATORES AMBIENTAIS NA PRODUTIVIDADE DA CULTURA DO MILHO NA REGIÃO DE JANAÚBA, MG}

variações na temperatura do ar pelo fato de ser o sol o principal responsável pelo comportamento temporal da temperatura do ar (VAREJÃO-SILVA, 2005). Devido a tais singularidades ou eventualidades que $\mathrm{o}$ fator ano de plantio possui um percentual menor de influência na variabilidade da produtividade da cultura, conforme se observou nos resultados apresentados na Tabela 3.

Com base nesta análise inicial, procedeu-se, então, uma análise mais detalhada, tendo sido feita a comparação entre os dois níveis do fator irrigação considerando os 1664 tratamentos (combinação de 52 datas de semeadura X 32 anos de plantio), usando $\mathrm{o}$ teste de comparações múltiplas de Tukey com nível de significância de $5 \%$.

Houve uma diferença significativa entre níveis de irrigação em $70,4 \%$ dos tratamentos (1172 tratamentos), enquanto que para $29,6 \%$ (492 tratamentos) essa diferença não foi significativa. Destaca-se que os $29,6 \%$ que não foram significativos, correspondem às épocas de plantio consideradas ótimas para o regime de sequeiro, compreendidas entre $10 \mathrm{de}$ outubro e 19 de dezembro, ou seja, que não apresentam déficit hídrico excessivo, de forma que as médias de produtividade de sequeiro, nesse período, não diferiram significativamente das médias de produtividade da cultura irrigada.

Quando comparadas as 104 combinações de data de semeadura $\mathrm{x}$ irrigação, tem-se que para 48 das 52 datas de semeadura $(92,3 \%)$, no caso irrigado, não houve diferença significativa no rendimento obtido ao longo dos 32 anos. Para as outras quatro datas (correspondentes às semanas 15 a 18 ou 7 a 28/Nov), houve diferença significativa de rendimento entre anos. Observam-se na Figura 4 as séries de rendimento ao longo dos anos para essas quatro datas de semeadura. A diferença significativa foi devida a dois anos com quebra acentuada de produtividade, sendo estes anos 1984 e 1991.

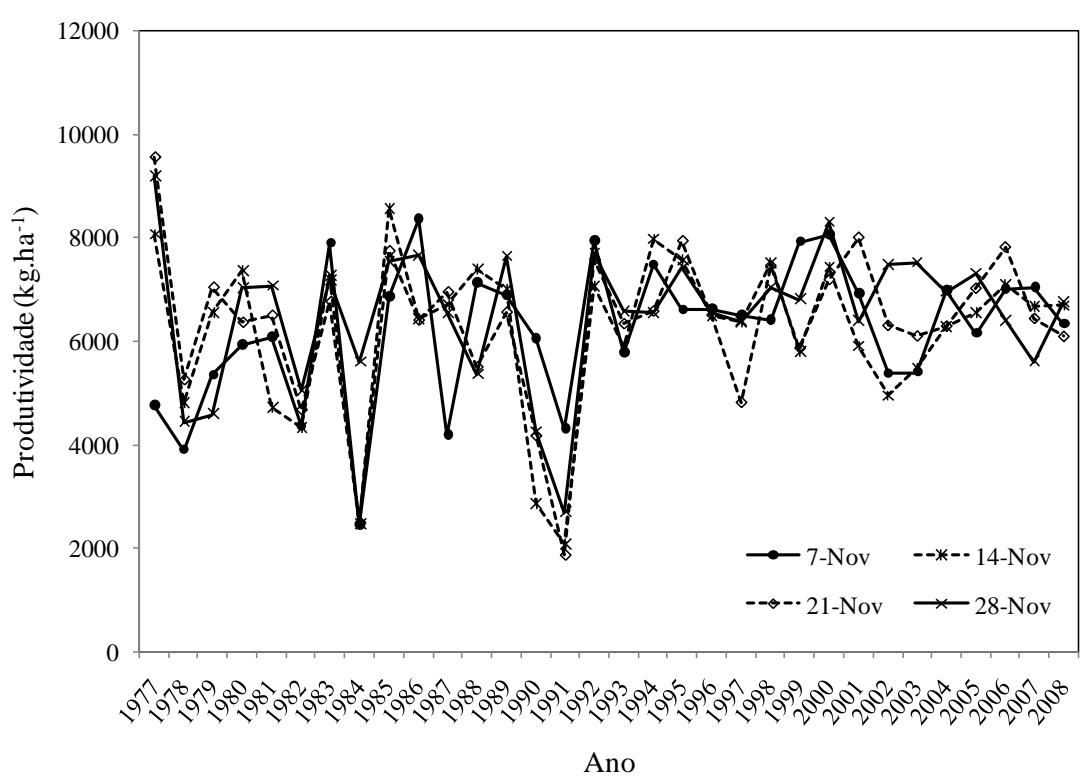

Figura 4: Valores de produtividades simuladas no período de 1977 a 2008 para as datas de semeadura 7, 14,21 e $28 /$ Nov. 


\section{IDENTIFICAÇÃO E QUANTIFICAÇÃO DO EFEITO DE FATORES AMBIENTAIS NA PRODUTIVIDADE DA CULTURA DO MILHO NA REGIÃO DE JANAÚBA, MG}

Confrontando estes resultados com os dados climáticos, notou-se que a queda da produtividade, observada nas referidas datas, coincidiu com a baixa radiação solar incidente durante o ciclo da cultura, conforme apresentado na Figura 5.

Nos anos 1984 e 1991 as produtividades atingiram valores médios de $2.300 \mathrm{~kg} \mathrm{ha}^{-1}$ para valores médios de radiação incidente de $15 \mathrm{MJ}$ $\mathrm{m}^{-2} \mathrm{~d}^{-1}$, contra valores médios totais de produtividade em torno de $6.300 \mathrm{~kg} \mathrm{ha}^{-1}$ para 20,2 $\mathrm{MJ} \mathrm{m}^{-2} \mathrm{~d}^{-1}$, observados nos demais anos. Fato semelhante foi

(A)

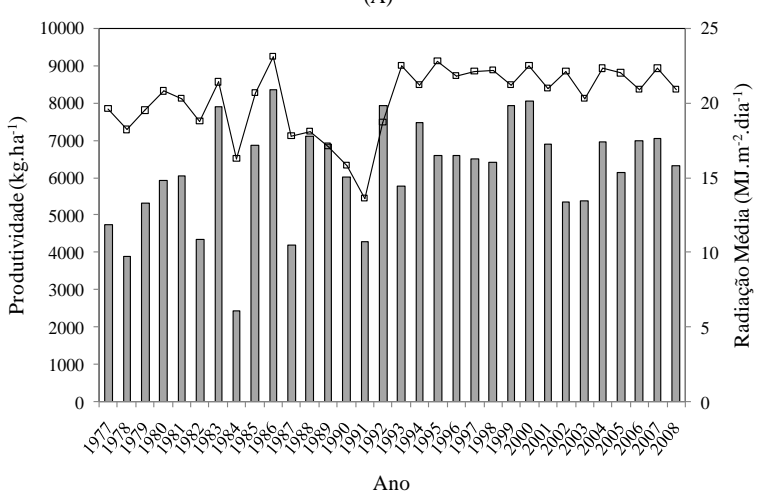

(C)

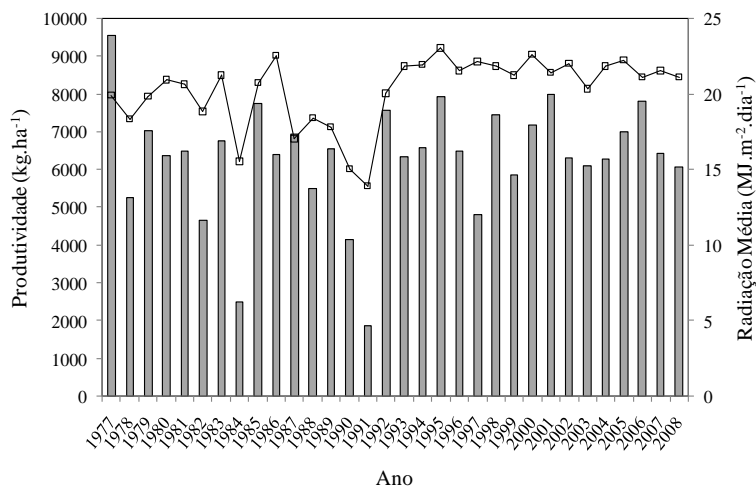

observado por Freitas et al. (2001), que constataram que a maior e a menor produtividade alcançada nos anos estudados corresponderam a maior e a menor radiação solar incidente média observada durante o ciclo da cultura, respectivamente, salientando que a produtividade é afetada mais pela distribuição da radiação ao longo do ciclo da cultura do que pela radiação média, propriamente dita, o que explica a ocorrência de diferentes produtividades entre os anos mesmo quando a radiação incidente tenha atingido valores médios semelhantes.
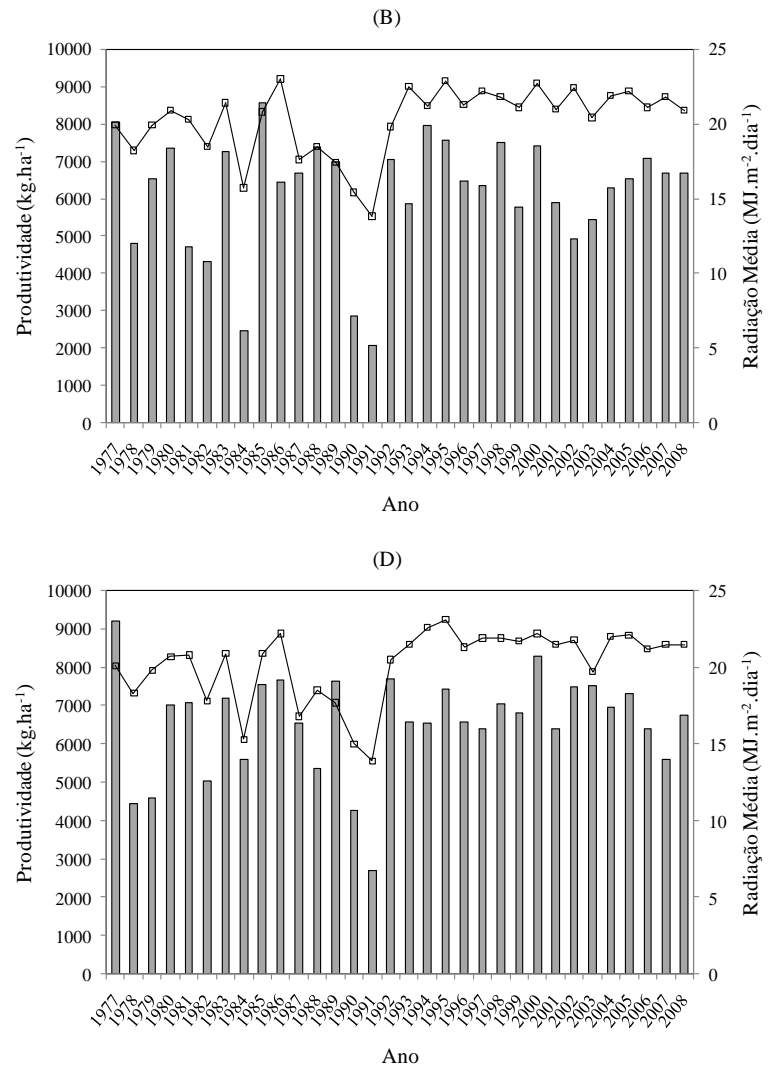

Figura 5: Valores de produtividades simuladas $(\square)$ e radiação solar global média $(\rightarrow-)$, no período de 1977 a 2008, para as datas de semeadura (7 (A), 14 (B), 21 (C) e 28/Nov (D)).

Fazendo a mesma comparação, ou seja, data de semeadura $\mathrm{x}$ irrigação, para o caso do regime de sequeiro, temse que apenas para 32 das 52 datas $(61,5 \%)$ não houve diferença significativa no rendimento obtido ao longo dos 32 anos. Para as outras 20 datas, correspondentes às semanas 12/Set a 23/Jan, houve diferença significativa de rendimento entre anos. 


\section{IDENTIFICAÇÃO E QUANTIFICAÇÃO DO EFEITO DE FATORES AMBIENTAIS NA PRODUTIVIDADE DA CULTURA DO MILHO NA REGIÃO DE JANAÚBA, MG}

Estas datas de semeadura compreendem o período chuvoso e a variabilidade observada nas produtividades se dá em função da ocorrência de secas em determinado ano ou a má distribuição das chuvas ao longo do ciclo da cultura. Percebe-se que, para o caso não irrigado a variabilidade interanual é muito maior do que para o irrigado, evidenciando a predominância da influência da disponibilidade hídrica na produtividade da cultura do milho em detrimento a outros fatores.

Destaca-se, ainda, a importância da distribuição das chuvas ao longo do ciclo da cultura. Segundo Kunz et al. (2007), a deficiência hídrica é uma das principais causas de perda de rendimento em milho, exercendo efeitos variados sobre a planta, dependendo de seu estádio de desenvolvimento, do nível da deficiência e da sua duração. Afirmação que também justifica os resultados encontrados para a análise da interação ano x irrigação. Neste último caso, quando comparadas as 64 combinações de ano x irrigação, tem-se que para nenhum dos 32 anos, no caso irrigado, houve diferença significativa no rendimento obtido ao longo das 52 datas de semeadura. Já para o caso não irrigado, em 17 dos 32 anos $(53,1 \%)$ houve diferenças significativas de rendimento entre datas de semeadura.

Diante do exposto, constata-se que os critérios para a definição de melhores datas de semeadura devem diferir em função das condições de manejo da cultura. No caso de cultivos de sequeiro, o fator predominante é a disponibilidade hídrica e sua distribuição ao longo do ciclo da cultura. Mas no caso de plantios irrigados, há que se observarem períodos de maior incidência de radiação e condições ótimas de temperatura, para que a planta atinja seu potencial produtivo. Visto que, de acordo com Assis et al. (2006), a obtenção de valores elevados de produtividade potencial se deve a combinação de valores adequados de temperatura e radiação solar.

\section{CONCLUSÕES}

Para o plantio do milho no município de Janaúba, MG, sob condições de cultivo de sequeiro, conclui-se que a disponibilidade hídrica responde por $61,9 \%$ da variação total da produtividade desta cultura, enquanto que os $38,1 \%$ restantes correspondem a fatores como data de semeadura e ano de plantio.

Em condições ótimas de disponibilidade hídrica (cultivo irrigado), os fatores, que mais influenciam o rendimento da cultura do milho são, basicamente, a variações de temperatura do ar e a radiação solar incidente. A influencia do fator radiação solar incidente evidenciou-se pela variação significativa da produtividade simulada para o cultivo irrigado nas datas de semeadura 7, 14, 21 e 28/Nov, devido a dois anos de quebra de produtividade, 1984 e 1991, em que se obtiveram produtividades médias de $2.300 \mathrm{~kg} \cdot \mathrm{ha}^{-1}$ para valores médios de radiação incidente de $15 \mathrm{MJ} \mathrm{m}^{-2} \mathrm{~d}^{-1}$, contra $6.300 \mathrm{~kg} \mathrm{ha}^{-1}$ de rendimento para $20,2 \mathrm{MJ} \mathrm{m}^{-2} \mathrm{~d}^{-1}$ de radiação incidente.

\section{AGRADECIMENTOS}

À FAPEMIG, pelo provimento da bolsa de pós-doutorado da primeira autora.

\section{REFERÊNCIAS}

ALBUQUERQUE, P. E. P. de. Cultivo do Milho - Irrigação. Sistemas de Produção 1, Embrapa Milho e Sorgo. Disponível em: http://www.cnpms.embrapa.br/publicac 


\section{IDENTIFICAÇÃO E QUANTIFICAÇÃO DO EFEITO DE FATORES AMBIENTAIS NA PRODUTIVIDADE DA CULTURA DO MILHO NA REGIÃO DE JANAÚBA, MG}

oes/milho_6_ed/imanejo.htm. Acesso em: 20/09/2011.

ANDRADE, F. H. Analysis of growth and yield of maize, sunflower and soybean grown at Balcarce, Argentina. Field Crops Research, v. 41, p. 1-12, 1995.

ANDRADE, C. L. T.; AMARAL, T. A.; SILVA, D. F.; HEINEMANN, A. B.; GARCIA, A. G. Y.; HOOGENBOOM, G ; MAGALHÃES, P. C.; ARAÚJO, S. G. A. Utilização do Modelo CERES-Maize como Ferramenta na Definição de Estratégias de Semeadura de Milho: 1 - Sistema de Produção de sequeiro. In: CONGRESSO BRASILEIRO DE AGROMETEOROLOGIA， 16，2009, Belo Horizonte. Resumos... Belo Horizonte: SBA. 1CD, 2009a.

ANDRADE, C. L. T.; AMARAL, T. A.; SILVA, D. F.; GARCIA, A. G. Y.; HOOGENBOOM, G.; GUIMARAES, D. P.; OLIVEIRA, A. C.; SANTANA, C. B. Utilização do Modelo CERESMaize como Ferramenta na Definição de Estratégias de Semeadura de Milho: 2 - Sistema de Produção Irrigado: In: CONGRESSO BRASILEIRO DE AGROMETEOROLOGIA， 16，2009, Belo Horizonte. Resumos... Belo Horizonte: SBA. 1CD, 2009b.

ANDRIOLI, K. G.; SENTELHAS, P. C. Brazilian maize genotypes sensitivity to water deficit estimated through a simple crop yield model. Pesquisa Agropecuária Brasileira, Brasília, v. 44, n. 7, p. 653-660, 2009

ASSIS, J. P. de; DOURADO NETO, D.; REICHARDT, K.; MANFRON, P. A.; MARTIN, T. N.; BONNECARRÈRE, R. A. G. Dados climáticos simulados e produtividade potencial do milho. Pesquisa Agropecuária Brasileira, v.41, n.5, p.731-737, 2006.

BERGAMASCHI, H.; DALMAGO, G. A.; COMIRAN, F.; BERGONCI, J. I.; MÜLlER, A. G.; SANTOS, A. O.; RADIN, B.; BIANCHI, C. A. M.; PEREIRA, P. G. Deficit hídrico e produtividade na cultura do milho. Pesquisa Agropecuária Brasileira, v.41, n.2, p.243-249, 2006.

BERGAMASCHI, H.; DALMAGO, G. A.; BERGONCI, J. I.; BIANCHI, C. A. M.; MÜllER, A. G.; COMIRAN, F.; HECKLER, B. M. M. Distribuição hídrica no período crítico do milho e produção de grãos. Pesquisa Agropecuária Brasileira, v. 39, p. 831839, 2004.

CRUZ, J. C.; PEREIRA FILHO, I. A.; ALVARENGA, R. C.; GONTIJO NETO, M. M.; VIANA, J. H. M.; OLIVEIRA, M. F.; MATRANGOLO, W. J. R.; ALBUQUERQUE FILHO, M. R. Cultivo do Milho. Sistemas de Produção 2, Embrapa Milho e Sorgo. Disponível em:

http://ainfo.cnptia.embrapa.br/digital/bitst ream/item/27037/1/Plantio.pdf. Acesso em: 17/02/2011.

DIDONET, A. D.; RODRIGUES, O.; MARIO, J. L.; IDE, F.; TISOT, D. Temperatura base para os subperíodos de desenvolvimento de híbridos de milho. In: REUNIÃO TÉCNICA ANUAL DO MILHO, 43.; REUNIÃO TÉCNICA ANUAL DO SORGO, 26., 1998, Veranópolis, Anais... Veranópolis: FEPAGRO, 1998. p. 100-101.

FANCELLI, A.L. Fisiologia, nutrição e adubação do milho para alto rendimento. In: SIMPÓSIO SOBRE ROTAÇÃO SOJA/MILHO NO 


\section{IDENTIFICAÇÃO E QUANTIFICAÇÃO DO EFEITO DE FATORES AMBIENTAIS NA PRODUTIVIDADE DA CULTURA DO MILHO NA REGIÃO DE JANAÚBA, MG}

PLANTIO DIRETO, 1.; 2000, Piracicaba, 2000. Anais... Piracicaba: IPNI, 2000. Disponível em: http://www.ipni.net/ppiweb/pbrazil.nsf/ 926048f0196c9d4285256983005c64de/ $7 \mathrm{ac} 877864218 \mathrm{~d} 46983256 \mathrm{c} 70005790 \mathrm{fc} /$ \$FILE/Anais\%20Antonio\%20Luiz\%20 Fancelli.doc. Acesso em: 04/01/2011.

FREITAS, P. S.; MANTOVANI, E. C.; REZENDE, R.; GONÇALVES, A. C. A.; BERTONHA, A. Influência da radiação solar sobre os valores de produtividade da cultura do milho, Zea mays L., simulados pelo modelo CERES-Maize. Acta Scientiarum, v. 23, n. 5, p. 1221-1227, 2001

FORSTHOFER, E. L.; SILVA, P. R. F.; STRIEDER, M. L.; MINETTO, T.; RAMBO, L.; ARGENTA, G.; SANGOI, L.; SUHRE, E.; SILVA, A. A. Desempenho agronômico e econômico do milho em diferentes níveis de manejo e épocas de semeadura. Pesquisa Agropecuária Brasileira, v. 41, n. 3, p. 399-407, 2006.

GOMES, E. N.; ESCOBEDO, J. F.; OLIVEIRA, A. P.; SOARES, J. Evolução diurna e anual da radiação direta na incidência. Avances en Energías Renovables y Medio Ambiente, vol. 10, p.129-136, 2006.

HOOGENBOOM, G.; JONES, J. W.; WILKENS, P. W.; PORTE, C. H.; HUNT, L. A.; BOOTE, K. J.; SINGH, U.; URYSEV, O.; LIZASO, J. I.; WHITE, J. W.; OGOSHI, R.; GIJSMAN, A. J.; BATHELOR, W. D.; TSUJ, G. Y. Decision Support System for Agrotechnology Transfer. Version 4.5. Honolulu: University of Hawaii, 2009. CD-ROM.

JONES, C. A. Ceres-Maize: A Simulation Model of Maize Growth and

Development.

Texas A \& M University Press. 1Ed, 194 p., 1986

KUNZ， J. H.; BERGONCI， J. I.; BERGAMASCHI, H.; DALMAGO, G. A.; HECKLER, B. M. M.; COMIRAN, F. Uso da radiação solar pelo milho sob diferentes preparos do solo, espaçamento e disponibilidade hídrica. Pesquisa Agropecuária Brasileira, v. 42, n. 11, p. 1511-1520, 2007.

LOZADA, B. I.; ANGELOCCI, L. R. Efeito da temperatura do ar e da disponibilidade hídrica do solo na duração de subperíodos e na produtividade de um híbrido de milho. Revista Brasileira de Agrometeorologia, v. 7, n. 1, p. 37-43, 1999.

PEIXOTO, C. M. Avanços tecnológicos da cultura do milho no Brasil. Portal Pionner. Disponível em: http://www.pioneersementes.com.br/Po pVersaoImpressaoArtigo.aspx?id=155. Acesso: 15/02/2011.

R DEVELOPMENT CORE TEAM. R: A language and environment for statistical computing. $\mathrm{R}$ Foundation for Statistical Computing, Vienna, Austria,. Disponível em: http://www.Rproject.org. Acesso 15/02/2010

SANTANA, C. B.; ANDRADE, C. L. T.; AMARAL, T. A.; SILVA, D. F.; MOURA, B. F.; CASTRO, L. A. Parametrização do modelo Ceres-Maize para cultivares de milho. In: I SEMINÁRIO DE INICIAÇÃO CIENTÍFICA PIBIC/BIC Júnior, 2010, Sete Lagoas.

TOJO SOLER, C.M. Uso do modelo Ceres-Maize para previsão de safra do milho "safrinha". 2004. 132 f. Tese 


\section{IDENTIFICAÇÃO E QUANTIFICAÇÃO DO EFEITO DE FATORES AMBIENTAIS NA PRODUTIVIDADE DA CULTURA DO MILHO NA REGIÃO DE JANAÚBA, MG}

(Doutorado), Escola Superior de Agricultura Luiz de Queiroz.

TUKEY, J. One degree of freedom for non-additivity. Biometrics, v. 5, n. 3, p. 232-242, 1949.

VAREJÃO-SILVA, M. A. Meteorologia e Climatologia. Versão digital, Recife, 2005. 522 p.

WILSON, D. R.; MUCHOW, R. C.; MURGATROYD C.J. Model analysis of temperature and solar radiation limitations to maize potential productivity in a cool climate. Field Crops Research, v. 43, p. 1-18, 1995. 